\title{
Early exposure to UV radiation causes telomere shortening and poorer condition later in life
}

$4 \quad$ Niclas U. Lundsgaard ${ }^{1 *}$, Rebecca L. Cramp ${ }^{1}$, Craig E. Franklin ${ }^{1}$

$5{ }^{1}$ School of Biological Sciences, The University of Queensland, Brisbane, 4072, Australia

6 * Corresponding Author

7 Niclas U. Lundsgaard

8 School of Biological Sciences

9 The University of Queensland,

10 Brisbane, Australia, 4072

11 niclas.lundsgaard@uq.net.au

12 Phone: +61416801116

13

14

Rebecca Cramp (‥cramp@uq.edu.au)

Craig Franklin (c.franklin@uq.edu.au)

\section{KEY WORDS}

19 Amphibian, carryover effect, irradiance, life-history trade-off, telomere length, ultraviolet 20 radiation. 


\section{UV-INDUCED TELOMERE SHORTENING LATER IN LIFE}

\section{AbSTRACT}

24 Determining the contribution of elevated ultraviolet-B radiation (UVBR; $280-315 \mathrm{~nm}$ ) to

25 amphibian population declines is being hindered by a lack of knowledge about how different

26 acute UVBR exposure regimes during early life history stages might affect post-metamorphic

27 stages via long-term carryover effects. We acutely exposed tadpoles of the Australian green

28 tree frog (Litoria caerulea) to a combination of different UVBR irradiances and doses in a

29 multi-factorial experiment, and then reared them to metamorphosis in the absence of UVBR

30 to assess carryover effects in subsequent juvenile frogs. Dose and irradiance of acute UVBR

31 exposure influenced carryover effects into metamorphosis in somewhat opposing manners.

32 Higher doses of UVBR exposure in larvae yielded improved rates of metamorphosis.

33 However, exposure at a high irradiance resulted in frogs metamorphosing smaller in size and

34 in poorer condition than frogs exposed to low and medium irradiance UVBR as larvae. We

35 also demonstrate some of the first empirical evidence of UVBR-induced telomere shortening

36 in vivo, which is one possible mechanism for life-history trade-offs impacting condition post-

37 metamorphosis. These findings contribute to our understanding of how acute UVBR

38 exposure regimes in early life affect later life-history stages, which has implications for how

39 this stressor may shape population dynamics.

41 SUMMARY STATEMENT

42 We demonstrate physiological carryover effects in amphibians that link larval UV exposure

43 to detrimental impacts on juvenile frogs, including telomere shortening, which has

44 implications for how UV shapes amphibian populations. 


\section{UV-INDUCED TELOMERE SHORTENING LATER IN LIFE}

\section{INTRODUCTION}

47 Solar ultraviolet-B radiation (UVBR; 280 to $315 \mathrm{~nm}$ ) is a high-energy electromagnetic

48 radiation and a pervasive stressor for many organisms (Williamson et al. 2019). In addition to

49 facilitating endogenous vitamin $\mathrm{D}_{3}$ synthesis (Stiffler 1993; Antwis and Browne 2009), this

50 genotoxic stressor can also form pyrimidine dimer lesions in DNA that disrupt transcription

51 and replication, which can in turn lead to cancer, cell apoptosis and tissue damage (Mitchell

52 and Nairn 1989; Batista et al. 2009; Londero et al. 2019). UVBR also causes oxidative stress

53 through the production of reactive oxygen species (ROS; Heck et al. 2003; Kazerouni et al.

54 2016), although ultraviolet-A radiation (UVAR; 315-400 nm) is more potent in this regard

55 (Schuch et al. 2017). Despite organisms having DNA repair mechanisms to remove UVBR-

56 induced DNA damage (Sancar and Sancar 1988; Sancar and Tang 1993; Schuch et al.,

57 2015b), even minor increases in UVBR irradiance may be sufficient to tip DNA damage rates

58 beyond the capacity for repair, which can have detrimental downstream effects on organismal

59 condition and survival (Blaustein et al. 1994, Pandelova et al. 2006, Schuch et al. 2015b).

60 Stratospheric ozone depletion and changes in climate have caused widespread increases in the

61 irradiance and fluctuation of UVBR in regions of amphibian decline (Farman et al. 1985;

62 Kerr and McElroy 1993; Herman et al. 1996; McKenzie et al. 1999; Middleton et al. 2001;

63 Schuch et al. 2015a). Ambient UVBR can have a range of lethal and sublethal effects across

64 many amphibian species (Blaustein et al. 1995; Tietge et al. 2001; Blaustein et al. 2005;

65 Bancroft et al. 2008; Croteau et al. 2008; Cramp and Franklin 2018), and these effects may be

66 exacerbated by interactions with other factors including disease, pollutants and temperature

67 (Blaustein and Keisecker 2002; Blaustein et al. 2003; Alton and Franklin 2017; Lundsgaard

68 et al. 2020). However, two significant gaps in this body of literature hinder the effective

69 extrapolation of these individual-level effects of UVBR to population-scale effects and

70 declines. Firstly, it is not known which parameters of UVBR exposure determine amphibian

71 health risk, be it irradiance, dose or exposure duration (Lundsgaard et al. 2021), which leads

72 to discrepancies in the estimated risks posed to amphibians by field measurements of UVBR

73 (Palen et al. 2002; Blaustein et al. 2004; Olker et al. 2013). Secondly, most research has

74 focussed on early life-history stages which are most susceptible to UVBR exposure, but that

75 do not strongly drive population dynamics (Vonesh and De la Cruz 2002; Vonesh 2005).

76 Post-metamorphic life-history stages have the strongest influence on amphibian population

77 dynamics (Biek et al. 2002) but are typically overlooked in UVBR research due to their

78 mainly nocturnal habits (Bancroft et al. 2008). What is rarely considered are potential 


\section{UV-INDUCED TELOMERE SHORTENING LATER IN LIFE}

physiological carryover effects that link embryonic and larval UVBR exposure to impacts on post-metamorphic life stages, despite the implications that such effects would have for amphibian population dynamics (Van Allen et al. 2010).

Carryover effects are consequences of an early development experience that persist for a time after the experience that causes them ceases, such that cause and effect are separated by a measurable transitional period (O'Connor et al. 2014). For example, environmental factors encountered by embryonic and larval amphibians, including contaminants, predation, aquatic $\mathrm{pH}$, food availability and conspecific density, have been shown to affect traits including locomotion, morphology, growth and survival in later life-history stages (Merila et al. 2000; Relyea 2001; Rasanen et al. 2002; Vonesh 2005; Chelgren et al. 2006; Tejedo et al. 2010; Van Allen et al. 2010; Boes and Benard 2013; Touchon et al. 2013; Rumrill et al. 2018). Only a few studies have explicitly tested carryover effects of UVBR exposure in amphibians, with detrimental effects of exposure during embryonic and larval stages oftentimes only manifesting in later life-history stages (Smith et al. 2000; Pahkala et al. 2001, 2003; Belden and Blaustein 2002; Ceccato et al. 2016). Such 'latent effects' are becoming increasingly apparent across taxa (Pechenik 2006), yet little is known about the mechanistic basis for these effects, with changes in energy balance, oxidative stress, epigenetic modifications, and telomere lengths all implicated (O'Connor et al. 2014; Young 2018).

Telomeres are non-coding DNA sequence repeats (TTAGGG in vertebrates) on the ends of chromosomes (in eukaryotes) and serve a protective role in maintaining genome stability (O’Sullivan and Karlseder, 2010). In metazoans, this highly conserved nucleoprotein structure is shortened during each cellular division cycle, and can also be damaged by oxidative stress, potentially accelerating the shortening process (Young 2018). Upon reaching a critical minimum length, replicative senescence is triggered in order to prevent mutation and cancer (Campisi and d'Adda di Fagagna 2007). For these reasons, telomere length is a good proxy for long-term organismal health and longevity (Shalev et al. 2013). Given that telomere length is influenced by environmental stress and predicts long-term condition, it is likely that telomere shortening may be involved in the generation of life-history trade-offs and carryover effects (Young 2018). To our knowledge, no study has investigated how UVBR exposure in early life might influence telomere lengths later in life. Improving understanding of how the dose, irradiance, and duration of UVBR exposure interact on such carryover effects is crucial for elucidating the impacts of complex and increasing natural 


\section{UV-INDUCED TELOMERE SHORTENING LATER IN LIFE}

111 UVBR exposures on long-term amphibian health (Hegglin and Shepherd 2009; Mckenzie et 112 al. 2011; Olker et al. 2013).

113 Our aim was to investigate how exposure of larvae to different doses and irradiances of acute

114 UVBR affects size, condition, performance, and relative telomere lengths post-

115 metamorphosis. We acutely exposed tadpoles of the Australian green tree frog (Litoria

116 caerulea, White 1790) to a combination of different UVBR irradiances and doses in a fully

117 factorial laboratory experiment, and then reared these larvae to metamorphosis, assessing a

118 suite of life-history and performance traits in the juvenile frogs upon development. UVBR

119 irradiance determines the rate of DNA damage production (Londero et al. 2019), so we

120 hypothesised that high irradiance UVBR would hinder successful metamorphosis, and would

121 be more detrimental to growth, jumping performance and foraging efficiency in juvenile

122 frogs than an equivalent dose of low irradiance UVBR. Given that animals exposed to high

123 irradiance UVBR are expected to experience reduced growth and increased oxidative stress,

124 both of which can shorten telomeres, we also hypothesised that this treatment would cause

125 shorter relative telomere lengths in metamorphs.

\section{MATERIALS AND METHODS}

127

\section{Ethics statement}

This research was approved by The University of Queensland Animal Ethics Committee (approval no. SBS/089/19 and 2021/AE000365) and animal collection permission was granted by the Queensland Department of Environment and Science (permit no.

WISP17421516).

\section{Study species}

Litoria caerulea (White 1790) is a common species distributed throughout northern and eastern Australia. The IUCN lists this species as 'Least Concern', however population declines have been documented in some regions (Berger et al. 1998). L. caerulea is relatively resilient to UVBR (Lundsgaard et al. 2021), which is consistent with its ecology, laying transparent gel egg masses in unsheltered, ephemeral water bodies that are exposed to UVBR levels of up to $500 \mu \mathrm{W} \mathrm{cm}{ }^{-2}$ (at water surface, van Uitregt et al. 2007). 


\section{UV-INDUCED TELOMERE SHORTENING LATER IN LIFE}

\section{Animal collection and husbandry}

142 Seven freshly laid L. caerulea egg masses were collected from flooded roadsides in southeast

143 Queensland, Australia, and transported to The University of Queensland in plastic bags

144 containing water from the collection site. Each clutch was maintained in a separate $5 \mathrm{~L}$ plastic

145 tank of carbon-filtered Brisbane city tap water and housed at $22.5 \pm 1{ }^{\circ} \mathrm{C}$ on a $12 \mathrm{~L}: 12 \mathrm{D}$

146 photoperiod regime using non-UVBR fluorescent lights. At the commencement of UVBR

147 exposure treatments four weeks post-laying, larvae (Gosner stage 25; Gosner 1960) were

148 individually housed in clear plastic containers $(1 \mathrm{~L} ; 15 \times 10 \times 7 \mathrm{~cm})$ filled to a depth of $5 \mathrm{~cm}$

149 with carbon-filtered Brisbane city water (see Experimental Design). Larvae remained in these

150 containers following UVBR exposure and were reared to metamorphosis on thawed spinach,

151 with half water changes (of carbon-filtered Brisbane city water) made twice per week to

152 maintain water quality. When larvae developed front legs (Gosner stage 42), containers were

153 partially emptied of water and angled such that metamorphosing animals could climb out of

154 the water. Newly metamorphosed juvenile frogs were held individually in their original

155 housing containers with perforated lids and soaked paper towel added as substrate. Frogs

156 were fed crickets and cockroaches every four days until completion of tests one month post-

157 metamorphosis, after which they were euthanised in a buffered Tricaine-S bath (MS-222;

158 Aqua-Life, Nanaimo, Canada; $0.5 \mathrm{~g} \mathrm{~L}^{-1}$ ).

\section{Experimental Design}

160 The experimental design employed in this study is also described in Lundsgaard et al. (2021)

161 which reported on an earlier phase of this larger experiment. Four-week-old, individually-

162 housed larvae $(n=160)$, were randomly allocated to one of ten UVBR treatments in a $3 \times 3$

163 factorial design (plus a no-UVBR treatment; $n=16$ per treatment) that were centred around

164 midday and administered in addition to the 12L:12D non-UVBR background lighting. Three

165 levels of UVBR irradiance (low: $8.7 \mu \mathrm{W} \mathrm{cm}{ }^{-2}$, medium: $35.5 \mu \mathrm{W} \mathrm{cm}^{-2}$, and high: $70 \mu \mathrm{W} \mathrm{cm}$

$166{ }^{2}$; Table S1) were fully crossed with three levels of UVBR dose (low: 1 day and

167 approximately $2.5 \mathrm{~kJ} \mathrm{~m}^{-2} \mathrm{UVBR}$, medium: 4 days and approximately $10 \mathrm{~kJ} \mathrm{~m}^{-2} \mathrm{UVBR}$, and

168 high: 8 days and approximately $20 \mathrm{~kJ} \mathrm{~cm}^{-2}$ UVBR; Table S1). To decouple dose and

169 irradiance, the daily time interval of exposure was adjusted for each irradiance treatment so

170 that daily dose remained constant $(8,4$ and 1 hour of exposure per day for the low, medium

171 and high irradiance treatments, respectively). Temperature during and after the UVBR

172 exposure period was cycled daily to represent summer conditions at the site of collection, 


\section{UV-INDUCED TELOMERE SHORTENING LATER IN LIFE}

173 ranging from $21-31^{\circ} \mathrm{C}$. Water temperatures of each treatment were measured during the

174 experiment using waterproof iButton temperature data loggers and ranged from $21.5^{\circ} \mathrm{C}$ to

$17529^{\circ} \mathrm{C}$. Additional temperature fluctuations associated with heat emitted by the UVBR lights

176 were minimised by placing trays of ice on 'buffer shelves' immediately underneath the high

177 irradiance UVBR treatment during exposure events.

178 After the acute UVBR exposures, larvae were reared to metamorphosis as described earlier

179 (Fig. 1). Age (from egg), size (mass, snout-to-vent length, tibiofibular length and interorbital

180 distance), and body condition (scaled mass index) were measured at metamorphosis (defined

181 as the full reabsorption of the tail at Gosner stage 46). Growth rate of juvenile frogs in the

182 first month post-metamorphosis was also determined. One month after metamorphosis,

183 juvenile frogs were tested for jumping performance and foraging efficiency. Upon

184 completion of tests, frogs were euthanised in a MS-222 bath and carcasses were immediately

185 stored at $-80^{\circ} \mathrm{C}$ for analysis of relative telomere lengths (see Traits section for more details).

UVBR Exposures

UVBR conditions were generated using $1.2 \mathrm{~m}, 40 \mathrm{~W}$ fluorescent light tubes (no UVBR $=0$ zero bulbs; low irradiance $=$ two bulbs at $51 \mathrm{~cm}$; medium irradiance $=$ six bulbs at $27 \mathrm{~cm}$; high irradiance $=$ eight bulbs at $12 \mathrm{~cm}$; Repti-Glo 10.0, Exo Terra, Montreal, Canada). UVBR and ultraviolet-A (UVAR; $315-400 \mathrm{~nm}$ ) levels at the water surface of each container were measured using a radiometer/photometer (IL1400BL, International Light Inc., Newburyport, USA) to ensure consistent levels across experimental shelves.

Fluorescent lights are a suitable substitute for natural sunlight when housing reptiles and amphibians, emitting important biologically active wavelengths across the ultraviolet (UV), visible and infrared spectra (Baines et al. 2016). That said, the physiological effects of artificial lighting cannot be directly extrapolated to sunlight exposure because of differences in spectral composition (Baines et al. 2016). Daily, natural fluctuations of UVBR and UVAR irradiances are correlated (Schuch et al. 2015b), so the ratio of UVBR:UVAR was kept as similar as possible between treatments. UVBR levels used in this study are much lower than ambient UVBR levels measured in the region $\left(500 \mu \mathrm{W} \mathrm{cm}{ }^{-2}\right.$ in air at water level at midday in Brisbane, Australia; van Uitregt et al. 2007), to help account for attenuation by cloud cover, vegetation cover and dissolved organic matter that reduce aquatic UVBR levels in the wild (Palen et al. 2002; Palen and Schindler 2010; Olker et al. 2013; Alton and Franklin 2017). 


\section{UV-INDUCED TELOMERE SHORTENING LATER IN LIFE}

\section{Traits}

206

207

\section{Age, size and condition at metamorphosis}

Developing larvae were monitored daily, with age at metamorphosis defined as the number of days between egg laying and full reabsorption of the tail (Gosner 46). Juvenile frogs were weighed and photographed on the day of metamorphosis and again one month later, allowing for calculations of post-metamorphic growth. Snout-to-vent length, leg length (tibiofibular bone) and interorbital distance (length between the eyes) were determined from photographs (iPod touch $5^{\text {th }}$ generation, Apple, California, USA) of the dorsal surface of each frog (with a ruler for scale) using the software program ImageJ (National Institutes of Health, Bethesda, Maryland, USA).

Of the three linear size metrics measured, interorbital distance correlated most strongly with body mass and was therefore used in mass/length calculations of body condition, as suggested by Peig and Green (2009). Condition factor of juvenile frogs was calculated using the scaled mass index (SMI) method developed by Peig and Green (2009), which has been demonstrated as the most suitable and accurate condition index across a range of taxa (Peig and Green 2009, 2010; Brodeur et al. 2020). In accordance with Brodeur et al. (2020) who confirmed the applicability of this method for use in amphibians, we defined the scaling exponent $b$ through a non-linear power function regression (mass $=\alpha[\text { interorbital distance }]^{b}$ ) for the sample population (minus two outliers) which was: $\gamma=0.0012 x^{2.9624}\left(\mathrm{R}^{2}=0.793\right)$, to obtain size-independent SMI values. This scaling exponent conforms with allometric scaling observed in other taxa, which typically ranges between 2.5 and 3.2 (Green 2001). Two outliers did not fit the mass/length trend of the sample population $(\mathrm{n}=50)$ and were therefore removed from calculation of the regression, following Peig and Green (2009). SMI was calculated relative to the average interorbital distance of the sample population (7.32 $\mathrm{mm}$ ), giving the estimated mass that each frog (including the two outliers) would have at this fixed body size. Larger SMI values thus indicate larger energy reserves and provide an effective estimate of body condition (Peig and Green 2009).

\section{Foraging efficiency}

Four weeks post-metamorphosis, and following a four-day fasting period, juvenile frogs were tested for indices of foraging efficiency. Individual frogs were placed under a clear lid in the middle of a rectangular foraging arena $(17 \times 30 \times 10 \mathrm{~cm})$ for a five-minute adjustment period prior to testing. A cricket of known mass $(7-34 \mathrm{mg}$; average cricket to frog mass ratio = 


\section{UV-INDUCED TELOMERE SHORTENING LATER IN LIFE}

$2371: 27$, range $=1: 104-1: 10$ ) was then placed under a holding container at the opposite end of

238 the arena so that the frog was directly facing the cricket. Both holding containers were then

239 lifted simultaneously and the frog was allowed to freely hunt the cricket in the hunting arena.

240 The hunt was timed and recorded using a GoPro Hero 5 (at $120 \mathrm{fps}$ and 1080p) and was

241 terminated the moment the frog captured and swallowed the prey, or in some instances 'gave

242 up' on the hunt due to fatigue (defined as the point in time in which the frog stopped eliciting

243 stalking behaviour for $30 \mathrm{~s}$ or more). Frogs were then returned to the middle of the arena,

244 placed under a lid, and rested for five minutes. The procedure was repeated two more times

245 (three hunts per day), and these foraging efficiency tests were repeated again four days later.

246 Videos were played back (Tracker Video Analysis and Modelling Tool, Open Source

247 Physics) frame-by-frame by digitising the snout to determine the maximum successful strike

248 distance and strike speed (leading to prey capture), as well as the time in pursuit of prey until

249 capture. Only the longest and fastest strike was analysed, while the number of strikes and

250 time in pursuit data were averaged across the six trials per animal. Individual trials where no

251 stalking/hunting behaviour was elicited were excluded from analyses. Two animals did not

252 elicit any stalking/hunting behaviour during the trials, instead attempting to escape the

253 foraging arena, or not responding to the presence of prey. Thus, these animals were excluded

254 from analysis.

255 Jumping performance

256 Four weeks post-metamorphosis, and two days after the first foraging efficiency test, the

257 same juvenile frogs were tested for jumping performance. Frogs were placed on top of

258 laminated grid paper and filmed immediately (GoPro Hero 5, $240 \mathrm{fps}$ at 720p) while

259 maximum escape behaviour was being elicited. Frogs that remained stationary were urged to

260 jump by gentle contact to the vent. After at least five jumps, frogs were returned to the

261 middle of the grid paper, placed under a lid, and rested for five minutes. The jump tests were

262 then repeated once more. Recordings were played back (Tracker Video Analysis and

263 Modelling Tool, Open Source Physics) frame-by-frame by digitising the snout to determine

264 the maximum jump length and speed. The longest and fastest jump recorded was considered

265 as the maximum jumping performance of the animal and used for analysis. If frogs jumped

266 further or faster in a foraging efficiency trial, then these jumps were considered as the

267 maximum jumping performance of the animal and used in the jumping performance analysis.

268 Two animals did not elicit measurable jumps despite repeated attempts and were excluded

269 from analysis. 


\section{UV-INDUCED TELOMERE SHORTENING LATER IN LIFE}

270

271

272

273

274

\section{Relative telomere lengths by qPCR}

The qPCR-based relative telomere length assay followed Burraco et al. (2017). Approximately $10 \mathrm{mg}$ (6-17 mg) of hind-leg muscle tissue was dissected (on ice) from each juvenile frog carcass $(n=2-8$ per treatment). Genomic DNA was extracted from the finely chopped muscle tissue using a PureLink Genomic DNA Mini Kit (Invitrogen, 5791 Van Allen Way Carlsbad, CA, USA), in accordance with the manufacturer's protocol. DNA concentrations were then determined using a Qubit fluorometer (Invitrogen, CA, USA, Cat \# Q32857) and a Qubit dsDNA Broad-Range Assay Kit (Invitrogen, CA, USA, Cat \# Q32853), in accordance with the manufacturer's protocol. DNA samples were aliquoted and stored at $80^{\circ} \mathrm{C}$ until use.

The broadly conserved nature of telomeric sequence repeats in vertebrates allowed us to use the same primer set as Burraco et al. (2017), i.e. F: 5-AACCAGCCAAGTACGATGACAT3' and R: 5'-CCATCAGCAGCAGCCTTCA-3. Species-specific Quantitative PCR (qPCR) primers against the glyceraldehyde-3-phosphate dehydrogenase (GAPDH) housekeeping gene were designed using PrimerQuest (Integrated DNA Technologies, IA, USA) with acceptance of the default parameters, except that amplicon length was set to 95-105 bp. The GAPDH primers were: F: 5'CGGTTTGTTTGGGTTTGGGTTTGGGTTTGGGTTTGGGTT3', and R: 5'-GGCTTGCCTTACCCTTACCCTTACCCTTACCCTTACCCT-3'. qPCR was performed using iTaq Universal SYBR Green Supermix (Bio-Rad Laboratories Inc.). We used a 1:40 dilution of DNA samples to suit both the telomere and GAPDH primer amplification rates. qPCR for telomere and GAPDH genes were performed on separate plates, but in corresponding wells for each sample. We used $1.75 \mathrm{ng}$ of genomic DNA per reaction, and primer concentrations of $500 \mathrm{nM}$ in a $20 \mu \mathrm{L}$ reaction containing $10 \mu \mathrm{L} 2 \times$ SYBR Green Supermix. PCR cycles for amplification of telomeric repeats were $5 \mathrm{~min}$ at $95^{\circ} \mathrm{C}$, and then 30 cycles of $1 \mathrm{~min}$ at $56^{\circ} \mathrm{C}$ and $30 \mathrm{~s}$ at $95^{\circ} \mathrm{C}$. For GAPDH, the $5 \mathrm{~min}$ incubation at $95^{\circ} \mathrm{C}$ was followed by 40 cycles of $1 \mathrm{~min}$ at $60^{\circ} \mathrm{C}$ and $95^{\circ} \mathrm{C}$ for $30 \mathrm{~s}$. All qPCR cycles were conducted on a Bio-Rad CFX Connect Real-Time System. The efficiency of each qPCR plate performed was determined from a standard curve by serially diluting a combined pool of all the samples (4-fold dilutions to 1:1024 concentration, and corresponding to 70.6, $17.65,4.413,1.103$ and $0.276 \mathrm{ng}$ of DNA per well). Samples were run in duplicate, and each assay included a separate standard curve as well as a no-template control (in triplicate) at the start and end of the plate (to detect any contamination associated with pipetting). 


\section{UV-INDUCED TELOMERE SHORTENING LATER IN LIFE}

302 All PCR efficiencies were above 95\%, and unique dissociation curves were produced in all assays. Contamination in no-template control wells ( $\mathrm{Ct}$ value of 30, relative to telomere $\mathrm{Ct}$ values of approximately 16.3) could not be avoided despite all efforts. Vasilishina et al. (2019) notes that contamination is not uncommon for this method, and that this should not affect results of relative telomere length evaluation. Data were collected using Bio-Rad CXF Manager software (version 3.1, Bio-Rad), and results were exported to Excel. Relative telomere length was quantified from averaged $\mathrm{Ct}$ values in accordance with Vasilishina et al. (2019) by normalising to the reference DNA sample: $\Delta \Delta C t=\Delta C t_{\text {sample }}-\Delta C t_{\text {reference }}$, where $\Delta C t=C t_{T E L}-C t_{G A P D H}$ for each sample. $\Delta \Delta C t$ values were used in statistical analysis and fold change in telomere length relative to the reference DNA sample was calculated for graphical display, where fold change $=2^{-\Delta \Delta C t}($ Pfaffl 2001).

\section{Statistical Analysis}

Statistical analyses were performed using R version 3.4.2 ("Short Summer"; R Core Team 2017). Data are presented as means \pm standard error, unless otherwise stated, and egg clutch was included as a random effect in all models where it accounted for significant variance. Where interactive effects were non-significant, they were systematically removed to generate the simplest model representative of the data. The no-UVBR treatments proved detrimental to larval fitness for this species (Lundsgaard et al. 2021), resulting in insufficient metamorphs for statistical analysis (Fig. 1). Therefore, the no-UVBR treatment was excluded from analyses.

Treatment-specific effects on the proportion of animals metamorphosing were modelled with a binomial generalised linear model (GLM; function $\mathrm{glm}$ ), whilst average age at metamorphosis was modelled with a linear mixed effects (LME) model (lmerTest package, function lmer; Kuznetsova et al. 2017). Additionally, a holistic analysis of treatment effects on the progression of metamorphosis over time was assessed with a Cox mixed effects survival analysis utilising the coxme (Therneau, 2018), Matrix (Bates and Maechler 2017) and survival (Therneau and Grambsch 2000; Therneau 2015) packages.

The correlation between age and mass at metamorphosis was assessed with a simple linear regression of the whole sample population. Treatment-specific differences in body mass and SMI of metamorphs were modelled with LME models. Following Alton and Franklin (2012), the correlation matrix of body mass, snout-to-vent length, interorbital distance, and leg length was assessed with a principal components analysis (PCA) to investigate treatment-associated 


\section{UV-INDUCED TELOMERE SHORTENING LATER IN LIFE}

334 differences in overall body size at metamorphosis. Of the resulting morphological variables

335 generated, principal component (PC) 1 accounted for $79.43 \%$ of the variation, and PC2

336 accounted for $11.17 \%$ of the variation. The PC factor scores for PC1 were then modelled with

337 an LME model. PC2 did not explain sufficient variation to be of particular interest (Quinn

338 and Keough 2002), and so was not assessed. To assess treatment-associated differences in the

339 growth of juvenile frogs in terms of overall body size, a PCA was performed using the same

340 morphological measurements at one month post-metamorphosis. PC1 accounted for $86.28 \%$

341 of the variation and was used in analysis, while PC2 did not explain sufficient variation to be

342 retained for further analysis (7.02\%). The PC1 factor scores were modelled with an LME

343 model with the PC1 factor scores from the initial size-at-metamorphosis data included as a

344 covariate.

345 The data for prey capture time as well as average and maximum strike attempts needed for

346 successful prey capture were skewed, and therefore modelled with negative binomial GLMs

347 (Mass package, function glm.nb; Venables and Ripley 2002) with frog mass included as a

348 covariate. Cricket mass was also included as a covariate in the analysis of maximum strike

349 attempts until prey capture. Maximum distance and speed for both jumping performance and

350 successful prey strikes were analysed with LME models. Frog leg length (tibiofibular length)

351 was included as a covariate for jumping performance models, while frog mass was a better

352 predictor in models of maximum strike distance and speed. $\Delta \Delta C t$ values (a proxy for

353 telomere lengths) were also modelled with an LME model with frog mass as a covariate.

354 Tukey contrasts were conducted post hoc using the multcomp package (function glht;

355 Hothorn et al. 2008).

\section{RESULTS}

357 The survival analysis revealed a significant effect of UVBR dose on the progression of 358 metamorphosis of $L$. caerulea larvae over time $\left(\chi^{2}{ }_{[2]}=7.742, P=0.021\right)$, with less than half 359 as many juvenile frogs developing in the low dose treatments compared to the medium and 360 high dose treatments $(Z=2.170, P=0.076 ; Z=2.602, P=0.025$, respectively; Fig. 2A).

361 However, there was no significant difference in the average age at metamorphosis of these

362 individuals $\left(F_{2,42}=0.099, P=0.906\right)$. There was no interaction between UVBR dose and 363 irradiance on the progression or average age at metamorphosis $\left(\chi_{[4]}^{2}=3.785, P=0.436 ; F_{4,36}\right.$ $364=2.012 ; P=0.113$, respectively), and no significant main effect of UVBR irradiance on these 


\section{UV-INDUCED TELOMERE SHORTENING LATER IN LIFE}

365 metrics (progression of metamorphosis: $\chi_{[2]}^{2}=4.970, P=0.083$; age at metamorphosis: $F_{2,41}$ $366=0.906, P=0.412$, respectively; Fig. 2B).

367 There was a moderate positive correlation between age and mass at metamorphosis $\left(F_{1,48}=\right.$ $36816.54, P<0.001 ; \mathrm{R}^{2}=0.256$, Fig. 3 ), with age at metamorphosis a strong predictor of 369 metamorph mass in the LME model $\left(F_{1,40}=17.641, P<0.001\right)$. There was no interactive 370 effect of UVBR dose and irradiance on mass or overall size at metamorphosis $\left(F_{4,34}=0.249\right.$, $371 P=0.908 ; F_{4,36}=0.220, P=0.926$, respectively), and no main effect of UVBR dose on these 372 metrics (mass: $F_{2,39}=1.636, P=0.208$; overall size: $F_{2,41}=2.543, P=0.091$; Fig. 4A).

373 However, there was a marginal effect of UVBR irradiance on mass at metamorphosis $\left(F_{2,39}=\right.$ $3742.925, P=0.066)$. Given that UVBR irradiance and dose did not significantly affect age at metamorphosis (see previous paragraph), we justified the removal of this covariate from analysis to prevent confounding effects with mass, which in turn yielded a significant effect of UVBR irradiance, but still not dose, on mass at metamorphosis (irradiance: $F_{2,38}=4.094$, $P=0.025$; dose: $F_{2,39}=1.761, P=0.185$, respectively) and overall size at metamorphosis (irradiance: $F_{2,43}=3.504, P=0.039$; dose: $F_{2,43}=2.772, P=0.074$ ). Larvae exposed to high irradiance UVBR metamorphosed with $20 \%$ less mass, on average, than larvae exposed to the low and medium irradiance treatments $(Z=-2.617, P=0.024 ; Z=-2.443, P=0.039$, respectively; Fig. 4B). Size at metamorphosis in turn predicted body size in the month following $\left(F_{1,38}=96.867, P<0.001\right)$, but there was no significant effect of larval UVBR treatment on growth during this time (dose: $F_{2,37}=0.305, P=0.739$, Fig. $4 \mathrm{C}$; irradiance: $F_{2,37}$ $=0.784, P=0.464$, Fig. 4D; interaction: $F_{4,36}=1.203, P=0.326$ ).

There was a significant interaction between UVBR dose and irradiance on juvenile frog body condition (interaction: $F_{4,36}=2.797, P=0.040$ ), whereby the effect of UVBR dose depended on the irradiance at which it was administered. High UVBR dose exposure improved metamorph body condition when administered at a low irradiance but reduced body condition when administered at medium irradiance (Fig. 5). Larvae exposed to high irradiance UVBR had reduced body condition at metamorphosis regardless of the dose administered, with an average $7.6 \%$ reduction in mass when scaled for the average interorbital distance of the sample population, compared to the low and medium irradiance treatments. Because of these interactive effects, the low dose UVBR treatment yielded the greatest differences in body condition depending on the irradiance of administration, with larvae that received a low UVBR dose metamorphosing with the worst SMI when administered at a low irradiance, but the best SMI when administered at a medium irradiance $\left(t_{35}=-2.856, P=0.019\right.$; Fig. 5). 


\section{UV-INDUCED TELOMERE SHORTENING LATER IN LIFE}

398 There was no significant effect of larval UVBR treatment on foraging efficiency of

399 subsequent juvenile frogs, as measured by foraging time (dose: $\chi^{2}{ }_{[2]}=0.408, P=0.816$;

400 irradiance: $\chi_{[2]}^{2}=0.383, P=0.826$; interaction: $\left.\chi_{[4]}^{2}=2.241, P=0.692\right)$, average strike

401 attempts (dose: $\chi_{[2]}^{2}=1.573, P=0.455$; irradiance: $\chi_{[2]}^{2}=0.449, P=0.799$; interaction: $\chi_{[4]}^{2}=$

$4020.450, P=0.978$ ), maximum strike attempts (dose: $\chi_{[2]}^{2}=1.718, P=0.424$; irradiance: $\chi_{[2]}^{2}=$

$403 \quad 0.215, P=0.898$; interaction: $\left.\chi_{[4]}^{2}=1.098, P=0.895\right)$, maximum successful strike distance

404 (dose: $F_{2,37}=0.995, P=0.379$; irradiance: $F_{2,37}=1.151, P=0.327$; interaction: $F_{4,37}=1.795$,

$405 P=0.151$ ) and maximum successful strike speed (dose: $F_{2,37}=0.409, P=0.667$; irradiance:

$406 F_{2,37}=1.274, P=0.292$; interaction: $F_{4,37}=1.066, P=0.387$; Table 1). Cricket size did not

407 influence maximum strike attempts until successful prey capture $\left(\chi_{[1]}^{2}=0.081, P=0.775\right)$.

408 However, there was a significant effect of frog mass on foraging efficiency as measured by

409 maximum successful strike distance and strike speed $\left(F_{1,37}=13.338, P<0.001 ; F_{1,37}=9.435\right.$,

$410 P=0.004$, respectively), with larger frogs able to jump farther and faster when striking prey

411 (Fig. 6).

412 There was no significant effect of larval UVBR treatment on metamorph jumping distance

413 (dose: $F_{2,33}=0.130, P=0.879$; irradiance: $F_{2,32}=2.099, P=0.139$; interaction: $F_{4,33}=1.113$,

$414 P=0.367$ ) and maximum jumping speed (dose: $F_{2,38}=0.377, P=0.689$; irradiance: $F_{2,38}=$

$4150.250, P=0.780$; interaction: $F_{4,38}=0.202, P=0.936$; Table 1$)$. However, there was a

416 significant effect of frog size (especially tibiofibular length) on jumping performance as

417 measured by maximum jumping distance and maximum jump speed (jumping distance: $F_{1,37}$

$418=7.789, P=0.008$; jumping speed: $\left.F_{1,38}=13.442, P<0.001\right)$, with larger frogs able to jump

419 farther and faster (data not shown)

420 UVBR irradiance had a significant effect on relative telomere lengths $\left(F_{2,38}=5.573, P=\right.$

4210.008 ; Fig. 7B), with juvenile frogs exposed to medium irradiance UVBR as larvae having

422 shorter relative telomere lengths as frogs than those previously exposed to low and high

423 irradiance UVBR treatments $(Z=3.116, P=0.005 ; Z=-2.524, P=0.031$, respectively).

424 There was no interaction between larval UVBR dose and irradiance on relative telomere

425 lengths $\left(F_{4,33}=0.524, P=0.719\right)$, and no main effect of UVBR dose on this metric $\left(F_{2,38}=\right.$

$4260.146, P=0.865$; Fig. 7A). Frog mass (at the time of sampling) did not have a significant

427 effect on relative telomere lengths $\left(F_{1,38}=0.874, P=0.356\right)$. 


\section{UV-INDUCED TELOMERE SHORTENING LATER IN LIFE}

\section{DISCUSSION}

431 We present three major findings in this study. We found that dose and irradiance of acute

432 UVBR exposure in larvae both influence long-term carryover effects into metamorphosis in a

433 trait-specific manner. High irradiance UVBR had contrasting effects across different life-

434 history stages (Lundsgaard et al. 2021), with evidence for life-history trade-offs negatively

435 impacting condition at metamorphosis. Finally, we demonstrated empirical evidence of

436 telomere shortening associated with UVBR exposure. These findings contribute to our

437 understanding of how acute UVBR exposure regimes in early life affect later life-history

438 stages in amphibians, further elucidating the role of this pervasive stressor in shaping

439 amphibian population dynamics.

440 In this study, four-week-old L. caerulea larvae (Gosner stage 25) exposed acutely to UVBR

441 experienced long-term carryover effects into the juvenile stage, driving changes in

442 metamorphosis, body condition and relative telomere lengths. Only a few other studies have

443 explicitly demonstrated carryover effects of UVBR exposure in amphibians through

444 metamorphosis (Pahkala et al. 2001, 2003; Ceccato et al. 2016). Pahkala et al. (2001) found

445 that embryos exposed to an enhanced dose of UVBR suffered from a higher prevalence of

446 developmental abnormalities as larvae, were delayed in metamorphosis, and were smaller as

447 juveniles compared to animals that were not exposed to UVBR. Ceccato et al. (2016) found

448 that a six-week exposure to UVBR in the larval phase led to immune system changes in

449 subsequent juvenile frogs. Our work corroborates the pervasive nature of UVBR-induced

450 carryover effects in amphibians through metamorphosis, highlighting the need to consider

451 such long-term effects when modelling UVBR effects on amphibian populations.

452 The medium and high UVBR dose treatments significantly improved progression into

453 metamorphosis compared to the low dose treatment, with reduced mortality throughout the

454 larval phase and during the transition through metamorphosis. These results support the

455 evidence for beneficial effects of high UVBR doses in this species, which include improved

456 growth, development, and swimming performance of larvae (Lundsgaard et al. 2021). These

457 results may reflect increased endogenous vitamin $\mathrm{D}_{3}$ synthesis in larvae and frogs previously

458 exposed to high UVBR doses, a vitamin essential for maintaining calcium homeostasis,

459 which in turn affects bone mineralisation, muscular function and nerve function (Stiffler

460 1993; Antwis and Browne 2009; Michaels et al. 2015). It is possible that a deficiency in

461 calcium stores hindered successful metamorphosis in animals that did not receive sufficient 


\section{UV-INDUCED TELOMERE SHORTENING LATER IN LIFE}

462 UVBR exposure, because of the need for increased bone formation during this time (Stiffler 463 1993).

464 Although the provision of high irradiance UVBR has been shown to benefit larval swimming 465 performance in this species (Lundsgaard et al. 2021), these benefits of high irradiance UVBR 466 did not carryover to foraging and jumping performance post-metamorphosis. In fact, larval 467 exposure to high irradiance UVBR had mainly detrimental carryover effects, resulting in 468 reduced size and poorer body condition at metamorphosis, both of which are associated with 469 reduced fitness and survival in amphibians (Chelgren et al. 2006; Scott et al. 2007). The 470 positive correlation between mass and some metrics of foraging efficiency in this study lend 471 further support to the detrimental fitness effects of reduced size at metamorphosis. As with 472 previous studies of UVBR-induced carryover effects on amphibian metamorphosis, the 473 detrimental effects of high UVBR irradiance were not evident in the life-history stage being 474 exposed (Lundsgaard et al. 2021), but instead manifested post-metamorphosis (Pahkala et al. 475 2001; Ceccato et al. 2016). These results highlight the importance of tracking fitness 476 consequences of UVBR exposure into later life-history stages, as such latent effects may 477 otherwise be missed. The contrasting effects of larval exposure to high irradiance UVBR across different life stages is evidence for a life-history trade-off that may be driven by changes in energy balance (Pechenik 2006). It is possible that the increased energy requirements for somatic maintenance in animals exposed to high irradiance UVBR as larvae may have led to reduced energy reserves being available at metamorphosis, as indicated by the lower SMI values (Alton et al. 2012). Such UVBR-induced life-history trade-offs have been observed in other taxa (Debecker et al. 2015).

484 The mechanisms driving the somewhat opposing effects of UVBR dose and irradiance on juvenile L. caerulea health are not known. However, it seems that certain post-metamorphic benefits conferred by a high dose of UVBR in the larval phase were only expressed at lower, more tolerable irradiances. This was particularly apparent with the SMI data. Although caution is warranted in interpretation given the small sample size, our data show a positive trend between metamorph body condition and UVBR dose when administered at a low

490 irradiance. At medium irradiance, beneficial effects of UVBR exposure are only conferred at 491 a low and medium dose, whilst any amount of exposure to high irradiance UVBR proved 492 detrimental to metamorph body condition. These results suggest that the effect of a given 493 UVBR dose are highly dependent on the irradiance at which it is administered at, which 494 highlights the importance of the rate of DNA damage production (determined by irradiance) 


\section{UV-INDUCED TELOMERE SHORTENING LATER IN LIFE}

495 for physiological outcomes (Pandelova et al. 2006; Londero et al. 2019). It seems that the

496 detrimental effects of even large doses can be managed if irradiance, and the rate of

497 formation of pyrimidine dimers in DNA, is low. If however, UVBR irradiance is great

498 enough that the rate of DNA damage exceeds the rate of DNA repair (dose-toxicity

499 threshold), then an accumulation of DNA damage is expected (Pandelova et al. 2006). This

500 accumulation of damage, or the rate at which it is induced, along with the energy required to

501 repair it, could explain the detrimental effects of the high irradiance UVBR treatments in later

502 life-history stages (Alton et al. 2012; Debecker et al. 2015). Namely, this molecular effect is

503 likely to influence energy use, oxidative stress, and even epigenetic modifications and

504 telomere lengths in exposed animals, all of which have been implicated as generators of

505 carryover effects (O’Connor et al. 2014; Young 2018).

506 Although high irradiance UVBR had the strongest impact on short-term fitness indices of $L$.

507 caerulea at metamorphosis, it was the medium irradiance treatment that had the greatest

508 impact on relative telomere lengths, which correlate with long-term fitness (Buracco et al.

509 2017). UV exposure is known to generate ROS which can damage and shorten telomeres

510 (Heck et al. 2003; Kazerouni et al. 2016; Young 2018), which may explain why relative

511 telomere lengths in animals exposed to medium irradiance UVBR were shorter than relative

512 telomere lengths in animals exposed to the low irradiance treatment. Larvae in the high

513 irradiance UVBR treatment likely experienced the greatest ROS levels, but this effect may

514 have been compensated for by a concomitant increase in molecular defence and repair

515 (including increased antioxidant capacity; Lundsgaard et al. 2020), thus reducing ROS-

516 induced telomere shortening. Such a compensatory response has been observed in western

517 spadefoot toad larvae (Pelobates cultripes) exposed to pond drying stress (Buracco et al.

518 2017), whereby relative telomere lengths remained unaffected, most likely due to an

519 upregulation in antioxidant capacity. Importantly, Burraco et al. (2017) also found that larvae

520 that metamorphosed larger and with more fat reserves had shorter telomeres, reflecting

521 increased metabolic rate, ROS production, and cell division in these animals (Savini et al.

522 2013; Burraco et al. 2017; Young 2018). A similar effect may have occurred in the present

523 study, whereby the reduced size and energy reserves of animals in the high irradiance UVBR

524 treatment reduced the overall sum of telomeric shortening effects, compared to animals in the

525 medium irradiance UVBR treatment. Our findings support the notion that a trade-off exists

526 between immediate/short-term fitness and long-term survivability and longevity in

527 amphibians responding to environmental stress (Burraco et al. 2017). Further research 


\section{UV-INDUCED TELOMERE SHORTENING LATER IN LIFE}

528 elucidating the complex interactions between stressors that cause telomere shortening, and variables that counteract telomere shortening (e.g. reduced growth) are warranted.

530 The finding that an acute, high irradiance exposure to UVBR in the larval period can have

531 short-term and long-term latent effects post-metamorphosis has important implications for

532 our understanding of how this stressor may be shaping amphibian population dynamics.

533 Studies of UVBR exposures in South and Central America suggest a doubling to tripling in

534 the frequency of short-term maximum UVBR exposure events in relatively recent times due

535 to changes in the distribution of ozone and cloud cover (Middleton et al. 2001; Schuch et al.

536 2015a). It is likely that similar increases in acute UVBR events will continue to occur in

537 some tropical regions due to climate change (Hegglin and Shepherd 2009; Mckenzie et al.

538 2011; Williamson et al. 2014). Although perturbations to early life-history stages of

539 amphibians may not drive population declines as much as previously assumed (Vonesh and

540 De la Cruz 2002; Vonesh 2005), the present study provides evidence for an additional

541 mechanism by which UVBR exposure in early-life-history stages could shape population

542 dynamics, by way of carryover effects into the crucial juvenile stage. Field measurements

543 taken to estimate the population-scale effects of UVBR exposure must jointly consider the

544 dose and irradiance of exposure to account for the complex interactive effects between these

545 UVBR parameters on long-term amphibian health.

\section{ACKNOWLEDGEMENTS}

547 The authors would like to thank Isabella Andresen, Katelyn Bell, Ilha Byrne, Jarrod

548 Cameron, Aimee Collier, Douglas Ledlie, Yufei (Lily) Pan, Sophie Smith and Terena Lucas-

549 Thornton for their assistance with animal maintenance, Dr Edward Meyer for spawn

550 collection, and Dr Pat Ward and Dr Simone Blomberg for statistical guidance.

\section{DECLARATION OF COMPETING INTERESTS}

552 No competing interests declared.

\section{FUNDING}

554 This research was financially supported by an Australian Research Council Discovery grant

555 (DP190102152 to C.E.F. and R.L.C.). N.U.L. was a recipient of a Research Training Program 556 scholarship. 


\section{UV-INDUCED TELOMERE SHORTENING LATER IN LIFE}

558

559

560

561

562

563

564

565

566

567

568

569

570

571

572

573

574

\section{REFERENCES}

Alroy J. 2015. Current extinction rates of reptiles and amphibians. P Natl Acad Sci USA 112:13003-13008. DOI: 10.1073/pnas.1508681112.

Alton L.A. and C.E. Franklin. 2012. Do high temperatures enhance the negative effects of ultraviolet-B radiation in embryonic and larval amphibians? Biol Open 1:897-903.

Alton L.A. and C.E. Franklin. 2017. Drivers of amphibian declines: effects of ultraviolet radiation and interactions with other environmental factors. Clim Chang Responses 4. DOI:10.1186/s40665-017-0034-7.

Alton L.A., C.R. White, R.S. Wilson, and C.E. Franklin. 2012. The energetic cost of exposure to UV radiation for tadpoles is greater when they live with predators. Funct Ecol 26:94-103.

Antwis R.E. and R.K. Browne. 2009. Ultraviolet radiation and Vitamin D-3 in amphibian health, behaviour, diet and conservation. Comp Biochem Phys A 154:184-190.

Baines F., J. Chattell, J. Dale, D. Garrick, I. Gill, M. Goetz, T. Skelton, and M. Swatman. 2016. How much UV-B does my reptile need? The UV-Tool, a guide to the selection of UV lighting for reptiles and amphibians in captivity. JZAR 4:42-63.

Bancroft B.A., N.J. Baker, and A.R. Blaustein. 2008. A meta-analysis of the effects of ultraviolet $\mathrm{B}$ radiation and its synergistic interactions with $\mathrm{pH}$, contaminants, and disease on amphibian survival. Conserv Biol 22:987-996.

Bates D. and M. Maechler. 2017. Matrix: sparse and dense matrix classes and methods. R package version 1.2-11. https://CRAN.R-project.org/package=Matrix.

Batista L.F.C., B. Kaina, R. Meneghini, and C.F.M. Menck. 2009. How DNA lesions are turned into powerful killing structures: Insights from UV-induced apoptosis. Mutat Res-Rev Mutat 681:197-208.

Belden L.K. and A.R. Blaustein. 2002. Exposure of red-legged frog embryos to ambient UVB in the field negatively affects larval growth and development. Oecologia 130:551554. 


\section{UV-INDUCED TELOMERE SHORTENING LATER IN LIFE}

Berger L., R. Speare, P. Daszak, D.E. Green, A.A. Cunningham, C.L. Goggin, R. Slocombe, M.A. Ragan, A.D. Hyatt, K.R. McDonald et al. 1998. Chytridiomycosis causes amphibian mortality associated with population declines in the rain forests of Australia and Central America. P Natl Acad Sci USA 95:9031-9036. DOI: 10.1073/pnas.95.15.9031

Biek R., W.C. Funk, B.A. Maxell, and L.S. Mills. 2002. What is missing in amphibian decline research: Insights from ecological sensitivity analysis. Conserv Biol 16:728734. DOI: 10.1046/j.1523-1739.2002.00433.x.

Blaustein A.R., B. Edmond, J.M. Kiesecker, J.J. Beatty, and D.G. Hokit. 1995. Ambient ultraviolet-radiation causes mortality in salamander eggs. Ecol Appl 5:740-743.

Blaustein A.R., B. Han, B. Fasy, J. Romansic, E.A. Scheessele, R.G. Anthony, A. Marco, D.P. Chivers, L.K. Belden, J.M. Kiesecker et al. 2004. Variable breeding phenology affects the exposure of amphibian embryos to ultraviolet radiation and optical characteristics of natural waters protect amphibians from UV-B in the US Pacific Northwest: Comment. Ecology 85:1747-1754.

Blaustein A.R., B.A. Han, R.A. Relyea, P.T.J. Johnson, J.C. Buck, S.S. Gervasi, and L.B. Kats. 2011. The complexity of amphibian population declines: understanding the role of cofactors in driving amphibian losses. Ann. N. Y. Acad. Sci. 1223:108-119.

Blaustein A.R., P.D. Hoffman, D.G. Hokit, J.M. Kiesecker, S.C. Walls, and J.B. Hays. 1994. UV repair and resistance to solar UV-B in amphibian eggs: a link to population declines? Proc Natl Acad Sci USA 91:1791-5.

Blaustein A.R. and J.M. Kiesecker. 2002. Complexity in conservation: lessons from the global decline of amphibian populations. Ecol Lett 5:597-608.

Blaustein A.R., J. M. Romansic, and A.C. Hatch. 2003. Ultraviolet radiation, toxic chemicals and amphibian population declines. Divers Distrib 9:123-140.

Blaustein A.R., J.M. Romansic, and E.A. Scheessele. 2005. Ambient levels of ultraviolet-B radiation cause mortality in juvenile western toads, Bufo Boreas. Am Midl Nat 154:375-382. 


\section{UV-INDUCED TELOMERE SHORTENING LATER IN LIFE}

613 Boes M.W. and M.F. Benard. 2013. Carry-over effects in nature: effects of canopy cover and individual pond on size, shape, and locomotor performance of metamorphosing wood frogs. Copeia 2013:717-722.

616

Brodeur J.C., M.J. Damonte, J.V. Candioti, M.B. Poliserpi, M.F. D’Andrea, and M.F. Bahl. 2020. Frog body condition: Basic assumptions, comparison of methods and characterization of natural variability with field data from Leptodactylus latrans. Ecol Indic 112. DOI:10.1016/j.ecolind.2020.106098.

Burraco P., C. Diaz-Paniagua, and I. Gomez-Mestre. 2017. Different effects of accelerated development and enhanced growth on oxidative stress and telomere shortening in amphibian larvae. Sci Rep 7. DOI: 10.1038/s41598-017-07201-z.

Campisi, J. and F. d'Adda di Fagagna. 2007. Cellular senescence: when bad things happen to good cells. Nat. Rev. Mol. Cell Bio 8: 729-740. DOI:10.1038/nrm2233.

Ceccato E., R.L. Cramp, F. Seebacher, and C.E. Franklin. 2016. Early exposure to ultraviolet$\mathrm{B}$ radiation decreases immune function later in life. Conserv Physiol 4. DOI:10.1093/conphys/cow037.

Chelgren N.D., D.K. Rosenberg, S.S. Heppell, and A.I. Gitelman. 2006. Carryover aquatic effects on survival of metamorphic frogs during pond emigration. Ecol Appl 16:250261.

Cohen J.M., D.J. Civitello, M.D. Venesky, T.A. McMahon, and J.R. Rohr. 2018. An interaction between climate change and infectious disease drove widespread amphibian declines. Glob Change Biol 25: 927-937. DOI: 10.1111/gcb.14489.

Cramp R.L. and C.E. Franklin. 2018. Exploring the link between ultraviolet B radiation and immune function in amphibians: implications for emerging infectious diseases. Conserv Physiol 6. DOI:10.1093/conphys/coy035.

Croteau M.C., M.A. Davidson, D.R.S. Lean, and V.L. Trudeau. 2008. Global increases in ultraviolet B radiation: potential impacts on amphibian development and metamorphosis. Physiol Biochem Zool 81:743-61. 


\section{UV-INDUCED TELOMERE SHORTENING LATER IN LIFE}

640 Debecker S., R. Sommaruga, T. Maes, and R. Stoks. 2015. Larval UV exposure impairs adult

641

642

immune function through a trade-off with larval investment in cuticular melanin. Funct Ecol 29:1292-1299.

Farman J.C., B.G. Gardiner, and J.D. Shanklin. 1985. Large losses of total ozone in Antarctica reveal seasonal ClOx/NOx interaction. Nature 315:207-210.

Gosner K.L. 1960. A simplified table for staging anuran embryos and larvae with notes on identification. Herpetologica 16:183-190.

Green A.J. 2001. Mass/length residuals: measures of body condition or generators of spurious results? Ecology 82:1473-1483.

Heck D.E., A.M. Vetrano, T.M. Mariano, and J.D. Laskin. 2003. UVB light stimulates production of reactive oxygen species - Unexpected role for catalase. J Biol Chem 278:22432-22436.

Hegglin M.I. and T.G. Shepherd. 2009. Large climate-induced changes in ultraviolet index and stratosphere-to-troposphere ozone flux. Nat Geosci 2:687-691.

Herman J.R., P.K. Bharti, J. Ziemk, Z. Ahma, and D. Larko. 1996. UV-B increases (19791992) from decreases in total ozone. Geophys Res Lett 23:2117-2120.

Hothorn T., F. Bretz, and P. Westfall. 2008. Simultaneous inference in general parametric models. Biometrical J 50:346-363.

International Union for Conservation of Nature. 2016. The IUCN Red List of Threatened Species. Version 2016-2. 2016. http://www.iucnredlist.org.

Kazerouni E.G., C.E. Franklin, and F. Seebacher. 2016. UV-B exposure reduces locomotor performance by impairing muscle function but not mitochondrial ATP production. $\mathrm{J}$ Exp Biol 219:96-102.

Kerr J.B. and C.T. McElroy. 1993. Evidence for large upward trends of ultraviolet-B radiation linked to ozone depletion. Science 262:1032-1034. 


\section{UV-INDUCED TELOMERE SHORTENING LATER IN LIFE}

665 Kuznetsova A., P.B. Brockhoff, and R.H.B. Christensen. 2017. lmerTest package: tests in 666 linear mixed effects models. J Stat Softw 82:1-26. DOI:10.18637/jss.v082.i13.

Londero J.E.L., M.B. dos Santos, and A.P. Schuch. 2019. Impact of solar UV radiation on amphibians: focus on genotoxic stress. Mutat Res Gen Tox En 842:14-21. DOI: 10.1016/j.mrgentox.2019.03.003.

Lundsgaard N.U., R.L. Cramp, and C.E. Franklin. 2020. Effects of ultraviolet-B radiation on physiology, immune function and survival is dependent on temperature: implications for amphibian declines. Conserv Physiol 8. DOI:10.1093/conphys/coaa002.

Lundsgaard N.U., R.L. Cramp, and C.E. Franklin. 2021. Ultraviolet-B radiation irradiance and cumulative dose combine to determine performance and survival. J Photoch Photobio B 222. DOI: 10.1016/j.mrgentox.2019.03.003.

McKenzie R.L., P.J. Aucamp, A.F. Bais, L.O. Bjorn, M. Ilyas, and S. Madronich. 2011. Ozone depletion and climate change: impacts on UV radiation. Photoch Photobio Sci 10:182-198. DOI: 10.1039/c0pp90034f.

McKenzie R., B. Connor, and G. Bodecker. 1999. Increased summertime UV radiation in New Zealand in response to ozone loss. Science 285:1709-1711.

Merila J., A. Laurila, M. Pahkala, K. Rasanen, and A.T. Laugen. 2000. Adaptive phenotypic plasticity in timing of metamorphosis in the common frog Rana temporaria. Ecoscience 7:18-24.

Michaels C.J., R.E. Antwis, and R.F. Preziosi. 2015. Impacts of UVB provision and dietary calcium content on serum vitamin D-3, growth rates, skeletal structure and coloration in captive oriental fire-bellied toads (Bombina orientalis). J Anim Physiol An N 99:391-403. DOI: 10.1111/jpn.12203.

Middleton E.M., J.R. Herman, E.A. Celarier, J.W. Wilkinson, C. Carey, and R.J. Rusin. 2001. Evaluating ultraviolet radiation exposure with satellite data at sites of amphibian declines in Central and South America. Conserv Biol 15:914-929. 


\section{UV-INDUCED TELOMERE SHORTENING LATER IN LIFE}

691 Mitchell D.L. and R.S. Nairn. 1989. The biology of the (6-4) photoproduct. Photochem

692 Photobiol 49:805-819.

O’Connor C.M., D.R. Norris, G.T. Crossin, and S.J. Cooke. 2014. Biological carryover effects: linking common concepts and mechanisms in ecology and evolution. Ecosphere 5. DOI:10.1890/ES13-00388.1.

Olker J.H., L.B. Johnson, R.P. Axler, and C.M. Johnson. 2013. Factors influencing ultraviolet radiation dose to developing frogs in northern vernal pools. Can J Fish Aquat Sci 70:1531-1541. DOI: 10.1139/cjfas-2013-0137.

O’Sullivan R.J. and J. Karlseder. 2010. Telomeres: protecting chromosomes against genome instability. Nat Rev Mol Cell Bio 11:171-181. DOI: 10.1038/nrm2848.

Pahkala M., A. Laurila, and J. Merila. 2001. Carry-over effects of ultraviolet-B radiation on larval fitness in Rana temporaria. P Roy Soc B-Biol Sci 268:1699-1706.

Pahkala M., J. Merila $\square$, I. Ots, and A. Laurila. 2003. Effects of ultraviolet-B radiation on metamorphic traits in the common frog Rana temporaria. J Zool 259: 57-62.

Palen W.J. and D.E. Schindler. 2010. Water clarity, maternal behavior, and physiology combine to eliminate UV radiation risk to amphibians in a montane landscape. P Natl Acad Sci USA 107:9701-9706. DOI: 10.1073/pnas.0912970107.

Palen W.J., D.E. Schindler, M.J. Adams, C.A. Pearl, R.B. Bury, and S.A. Diamond. 2002. Optical characteristics of natural waters protect amphibians from UV $\square$ B in the U.S. Pacific Northwest. Ecology 83:2951-2957.

Pandelova I., S.R. Hewitt, L.A. Rollins-Smith, and J.B. Hays. 2006. UVB dose-toxicity thresholds and steady-state DNA-photoproduct levels during chronic irradiation of inbred Xenopus laevis tadpoles. Photochem Photobiol 82:1080-1087.

Pechenik J.A. 2006. Larval experience and latent effects-metamorphosis is not a new beginning. Integr. Comp. Biol. 46: 323-33. DOI: 10.1093/icb/icj028.

Peig J. and A.J. Green. 2009. New perspectives for estimating body condition from mass/length data: the scaled mass index as an alternative. Oikos 118:1883-1891. 


\section{UV-INDUCED TELOMERE SHORTENING LATER IN LIFE}

718

719

720

721

722

Peig J. and A.J. Green. 2010. The paradigm of body condition: a critical reappraisal of current methods based on mass and length. Funct Ecol 24:1323-1332.

Pfaffl M.W. 2001. A new mathematical model for relative quantification in real-time RTPCR. Nucleic Acids Res 29. DOI: e45. DOI:10.1093/nar/29.9.e45.

Quinn G.P. and M.J. Keough. 2002. Experimental Design and Data Analysis for Biologists. Cambridge: Cambridge University Press.

Rasanen K., A. Laurila, and J. Merila. 2002. Carry-over effects of embryonic acid conditions on development and growth of Rana temporaria tadpoles. Freshw Biol 47:19-30.

R Core Team. 2017. R: A language and environment for statistical computing. R Foundation for Statistical Computing, Vienna. https://www.R-project.org/.

Relyea R.A. 2001. The lasting effects of adaptive plasticity: predator-induced tadpoles become long-legged frogs. Ecology 82:1947-1955.

Rumrill C.T., D.E. Scott, and S.L. Lance. 2018. Delayed effects and complex life cycles: How the larval aquatic environment influences terrestrial performance and survival. Environ Toxicol Chem 37:2660-2669.

Sancar A. and G.B. Sancar. 1988. DNA-repair enzymes. Annu Rev Biochem 57:29-67.

Sancar A. and M.S. Tang. 1993. Nucleotide excision repair. J Photoch Photobio B 57:90592.

Savini I., M.V. Catani, D. Evangelista, V. Gasperi, and L. Avigliano. 2013. Obesityassociated oxidative stress: strategies fnalized to improve redox state. Int. J. Mol. Sci. 14: 10497-538. DOI: 10.3390/ijms140510497.

Schuch A.P., M.B. dos Santos, V.M. Lipinski, L.V. Peres, C.P. dos Santos, S.Z. Cechin, N.J. Schuch, D.K. Pinheiro, and E.L.D.S. Loreto. 2015a. Identification of influential events concerning the Antarctic ozone hole over southern Brazil and the biological effects induced by UVB and UVA radiation in an endemic treefrog species. Ecotox Environ Safe 118:190-198. DOI: 10.1016/j.ecoenv.2015.04.029. 


\section{UV-INDUCED TELOMERE SHORTENING LATER IN LIFE}

Schuch A.P., V.M. Lipinski, M.B. Santos, C.P. Santos, S.S. Jardim, S.Z. Cechin, and E.L.S. Loreto. 2015b. Molecular and sensory mechanisms to mitigate sunlight-induced DNA damage in treefrog tadpoles. J Exp Biol 218:3059-3067.

Schuch A.P., N.C. Moreno, N.J. Schuch, C.F.M. Menck, and C.C.M. Garcia. 2017. Sunlight damage to cellular DNA: focus on oxidatively generated lesions. Free Rad. Biol. Med. 107 110-124.

Scott D.E., E.D. Casey, M.F. Donovan, and T.K. Lynch. 2007. Amphibian lipid levels at metamorphosis correlate to post-metamorphic terrestrial survival. Oecologia 153:521532.

Shalev C., S. Entringer, P.D. Wadhwa, O.M. Wolkowitz, E. Puterman, J. Lin, and E.S. Epel. 2013. Stress and telomere biology: A lifespan perspective. Psychoneuroendocrinology 38: 1835-1842. DOI: 10.1016/j.psyneuen.2013.03.010.

Smith G.R., M.A. Waters and J.E. Rettig. 2000. Consequences of embryonic UV-B exposure for embryos and tadpoles of the plains leopard frog. Con. Biol 14:1903-1907.

Stiffler D.F. 1993. Amphibian Calcium Metabolism. Joint Symp of the Company-ofBiologists/Soc-for-Experimental-Biology: Calcium Regulation and Signalling. Canterbury, England.

Stuart S.N., J.S. Chanson, N.A. Cox, B.E. Young, A.S.L. Rodrigues, D.L. Fischman, and R.W. Waller. 2004. Status and trends of amphibian declines and extinctions worldwide. Science 306:1783-1786.

Tejedo M., F. Marangoni, C. Pertoldi, A. Richter-Boix, A. Laurila, G. Orizaola, A.G. Nicieza, D. Alvarez, and I. Gomez-Mestre. 2010. Contrasting effects of environmental factors during larval stage on morphological plasticity in postmetamorphic frogs. Clim Res 43:31-46.

Therneau T.M. 2015. A package for survival analysis in S. version 2.38. https://CRAN.Rproject.org/package=survival. 


\section{UV-INDUCED TELOMERE SHORTENING LATER IN LIFE}

770

771

772

773

774

Therneau T.M. 2018. coxme: mixed effects cox models. R package version 2. 2-7. https://CRAN.R-project.org/package=coxme.

Therneau T.M. and P.M. Grambsch. 2000. Modeling survival data: extending the cox model. Springer, New York. ISBN 0-387-98784-3.

Tietge J.E., S.A. Diamond, G.T. Ankley, D.L. DeFoe, G.W. Holcombe, K.M. Jensen, S.J. Degitz, G.E. Elonen, and E. Hammer. 2001. Ambient solar UV radiation causes mortality in larvae of three species of Rana under controlled exposure conditions. Photochem Photobiol 74:261-268.

Touchon J.C., M.W. McCoy, J.R. Vonesh, and K.M. Warkentin. 2013. Effects of plastic hatching timing carry over through metamorphosis in red-eyed treefrogs. Ecology 94:850-860.

Van Allen B.G., V.S. Briggs, M.W. McCoy, and J.R. Vonesh. 2010. Carry-over effects of the larval environment on post-metamorphic performance in two hylid frogs. Oecologia 164:891-898.

van Uitregt V.O., R.S. Wilson, and C.E. Franklin. 2007. Cooler temperatures increase sensitivity to ultraviolet -B radiation in embryos and larvae of the frog Limnodynastes peronii. Glob Change Biol 13:1114-1121.

Vasilishina A., A. Kropotov, I. Spivak, and A. Bernadotte. 2019. Relative Human Telomere Length Quantification by Real-Time PCR. Methods in molecular biology (Clifton, N.J.). 1896: 39-44. DOI: 10.1007/978-1-4939-8931-7_5.

Venables W.N. and B.D. Ripley. 2002. Modern Applied Statistics with S, Fourth edition. Springer, New York. ISBN 0-387-95457-0, https://www.stats.ox.ac.uk/pub/MASS4/.

Vonesh J.R. 2005. Sequential predator effects across three life stages of the African tree frog, Hyperolius spinigularis. Oecologia 143:280-290.

Vonesh J.R. and O. De la Cruz. 2002. Complex life cycles and density dependence: assessing the contribution of egg mortality to amphibian declines. Oecologia 133:325-333. 


\section{UV-INDUCED TELOMERE SHORTENING LATER IN LIFE}

796 Williamson C.E., P.J. Neale, S. Hylander, K.C. Rose, F.L. Figueroa, S.A. Robinson, D.P.

797

798

799

800

801

802

803

804

805
Hader, S.A. Wangberg, and R.C. Worrest. 2019. The interactive effects of stratospheric ozone depletion, UV radiation, and climate change on aquatic ecosystems. Photoch Photobio Sci 18:717-746. DOI: 10.1039/c8pp90062k.

Williamson C.E., R.G. Zepp, R.M. Lucas, S. Madronich, A.T. Austin, C.L. Ballare, M. Norval, B. Sulzberger, A.F. Bais, R.L. McKenzie et al. 2014. Solar ultraviolet radiation in a changing climate. Nat Clim Change 4:434-441. DOI: 10.1038/NCLIMATE2225.

Young A.J. 2018. The role of telomeres in the mechanisms and evolution of life-history trade-offs and ageing. Philos T R Soc B 373. DOI:10.1098/rstb.2016.0452. 


\section{UV-INDUCED TELOMERE SHORTENING LATER IN LIFE}

TABLE

807

Table 1. Performance data for L. caerulea metamorphs in each UVBR treatment. No statistically significant treatment effects occurred.

\begin{tabular}{|c|c|c|c|c|c|c|c|c|}
\hline \multirow[t]{2}{*}{ Treatment } & & \multicolumn{5}{|c|}{ Foraging efficiency } & \multicolumn{2}{|c|}{ Jumping performance } \\
\hline & & $\begin{array}{l}\text { Foraging time } \\
\text { (s) }\end{array}$ & $\begin{array}{l}\text { Ave. strike } \\
\text { attempts }\end{array}$ & $\begin{array}{l}\text { Max. strike } \\
\text { attempts }\end{array}$ & $\begin{array}{l}\text { Max. strike } \\
\text { distance (mm) }\end{array}$ & $\begin{array}{l}\text { Max. strike speed } \\
(\mathrm{mm} / \mathrm{s})\end{array}$ & $\begin{array}{l}\text { Max. jump } \\
\text { distance (mm) }\end{array}$ & $\begin{array}{l}\text { Max. jump speed } \\
(\mathrm{mm} / \mathrm{s})\end{array}$ \\
\hline \multirow[t]{3}{*}{ Dose } & Low & $30.87 \pm 28.41$ & $3.45 \pm 1.94$ & $8.22 \pm 5.40$ & $56.30 \pm 24.20$ & $923.64 \pm 248.21$ & $115.76 \pm 33.48$ & $991.01 \pm 196.55$ \\
\hline & Medium & $33.92 \pm 39.04$ & $2.91 \pm 1.65$ & $6.53 \pm 4.03$ & $68.15 \pm 29.00$ & $954.84 \pm 273.16$ & $108.47 \pm 29.99$ & $1006.89 \pm 193.89$ \\
\hline & High & $22.37 \pm 23.37$ & $2.44 \pm 1.20$ & $5.56 \pm 3.40$ & $77.34 \pm 26.84$ & $1070.57 \pm 182.59$ & $117.67 \pm 29.18$ & $1011.36 \pm 92.04$ \\
\hline \multirow[t]{3}{*}{ Irradiance } & Low & $33.32 \pm 40.20$ & $2.93 \pm 1.65$ & $6.27 \pm 4.03$ & $64.27 \pm 33.36$ & $935.31 \pm 314.06$ & $108.35 \pm 36.92$ & $1009.11 \pm 188.31$ \\
\hline & Medium & $25.35 \pm 28.96$ & $2.76 \pm 1.67$ & $6.47 \pm 4.54$ & $76.51 \pm 25.43$ & $1049.52 \pm 187.52$ & $119.64 \pm 27.70$ & $1030.29 \pm 157.25$ \\
\hline & High & $27.43 \pm 22.78$ & $2.82 \pm 1.45$ & $6.71 \pm 3.99$ & $67.58 \pm 23.05$ & $1000.56 \pm 185.01$ & $113.17 \pm 23.06$ & $974.67 \pm 122.78$ \\
\hline
\end{tabular}




\section{UV-INDUCED TELOMERE SHORTENING LATER IN LIFE}

\section{$813 \quad$ Figures}

814

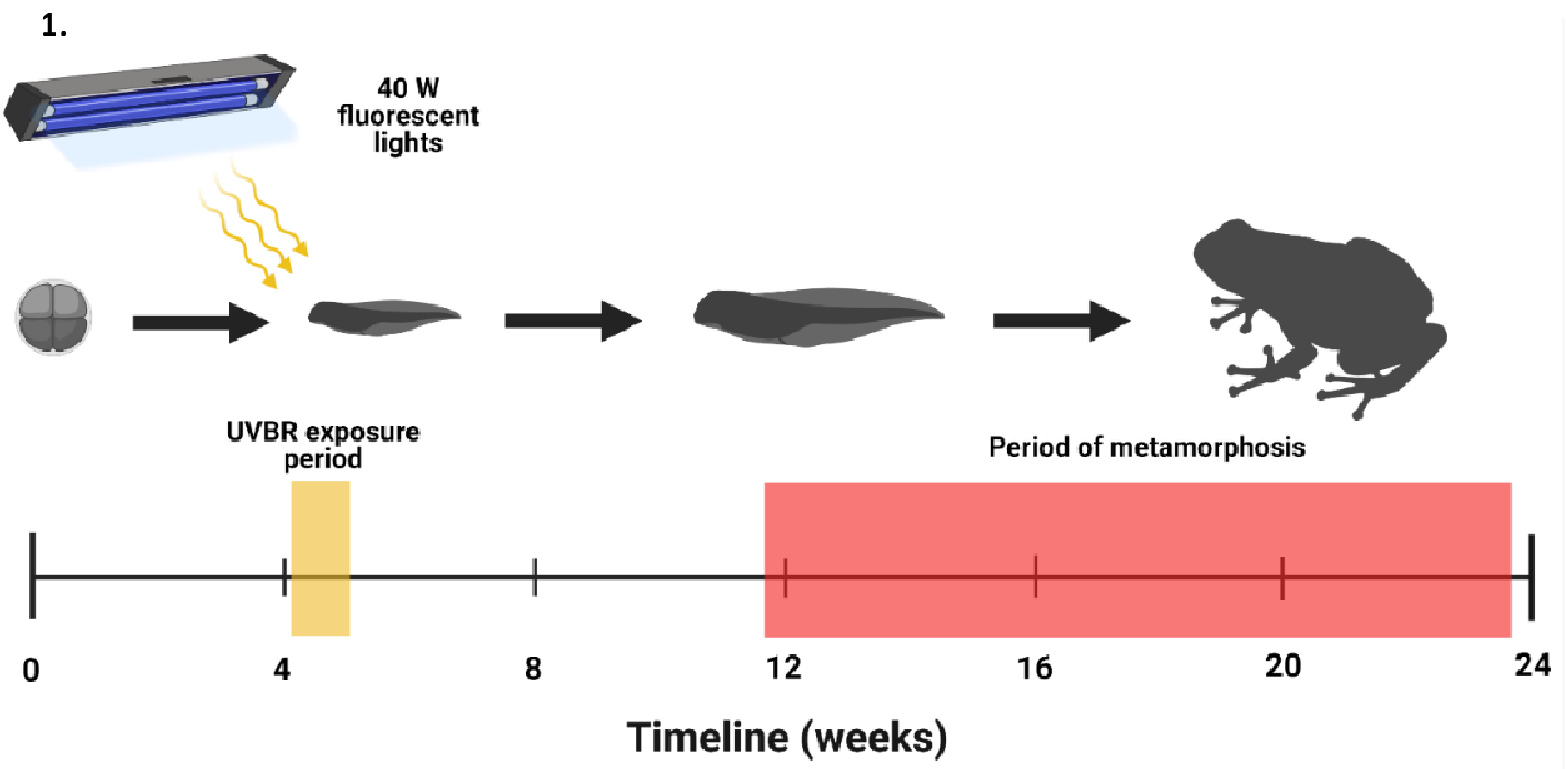

816 Figure 1. A schematic of the experimental timeline (in weeks). The yellow bar on the timeline represents the period of exposure of L. caerulea larvae (Gosner stage 25) to UVBR

818 treatments, whilst the time period in which metamorphosis occurred is demonstrated by the 819 red bar. The amphibian silhouettes are for illustrative purposes only. Created with 820 BioRender.com.

2. A

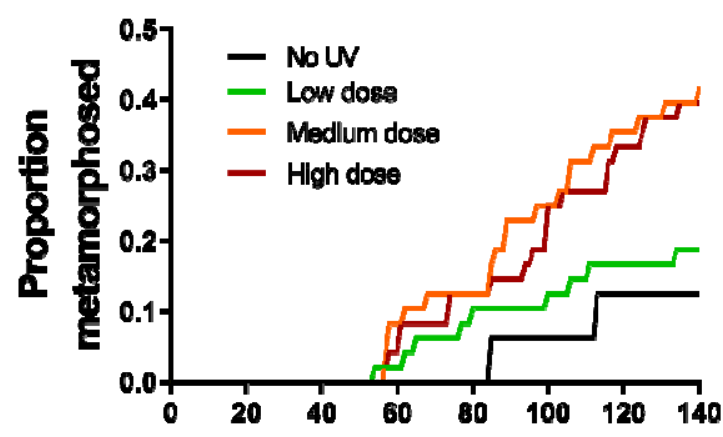

B

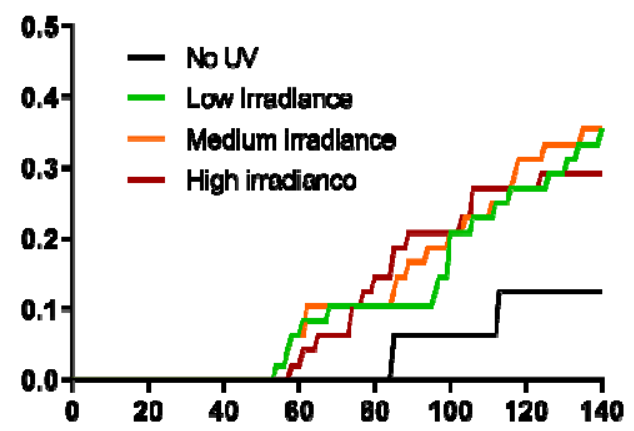

\section{Time (days)}

822 Figure 2. Effect of UVBR dose (A) and irradiance (B), on the progression of metamorphosis (as a proportion) of $L$. caerulea larvae over a 140-day period following commencement of treatments. No interaction between dose and irradiance was present, so data for the dose treatments are pooled across irradiances, and vice versa, to observe main effects ( $\mathrm{n}=48$ per treatment level). The no-UVBR control treatment (black line) is provided in both panels for reference $(n=16)$. 


\section{UV-INDUCED TELOMERE SHORTENING LATER IN LIFE}

828

829

830

\section{3.}

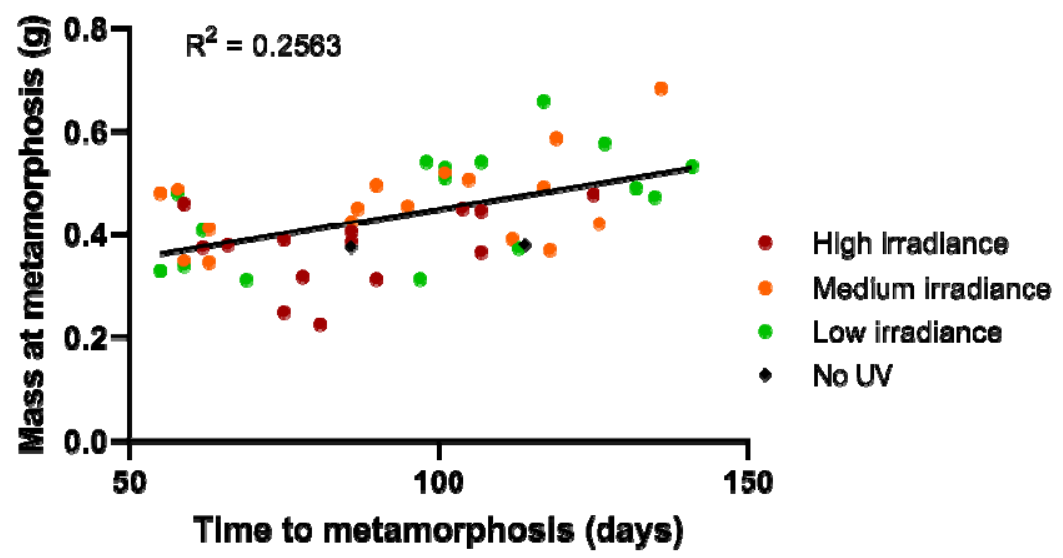

Figure 3. Correlation between age at metamorphosis and mass at metamorphosis (g) of L. caerulea larvae. Data points represent individual animals, color-coded by UVBR irradiance treatment ( $\mathrm{n}=14-17$ per irradiance, pooled across UVBR doses), with no-UVBR control animals indicated by black points $(n=2)$. Trend line indicates a moderate positive correlation between time to metamorphosis and mass $\left(\mathrm{R}^{2}=0.2563\right)$.
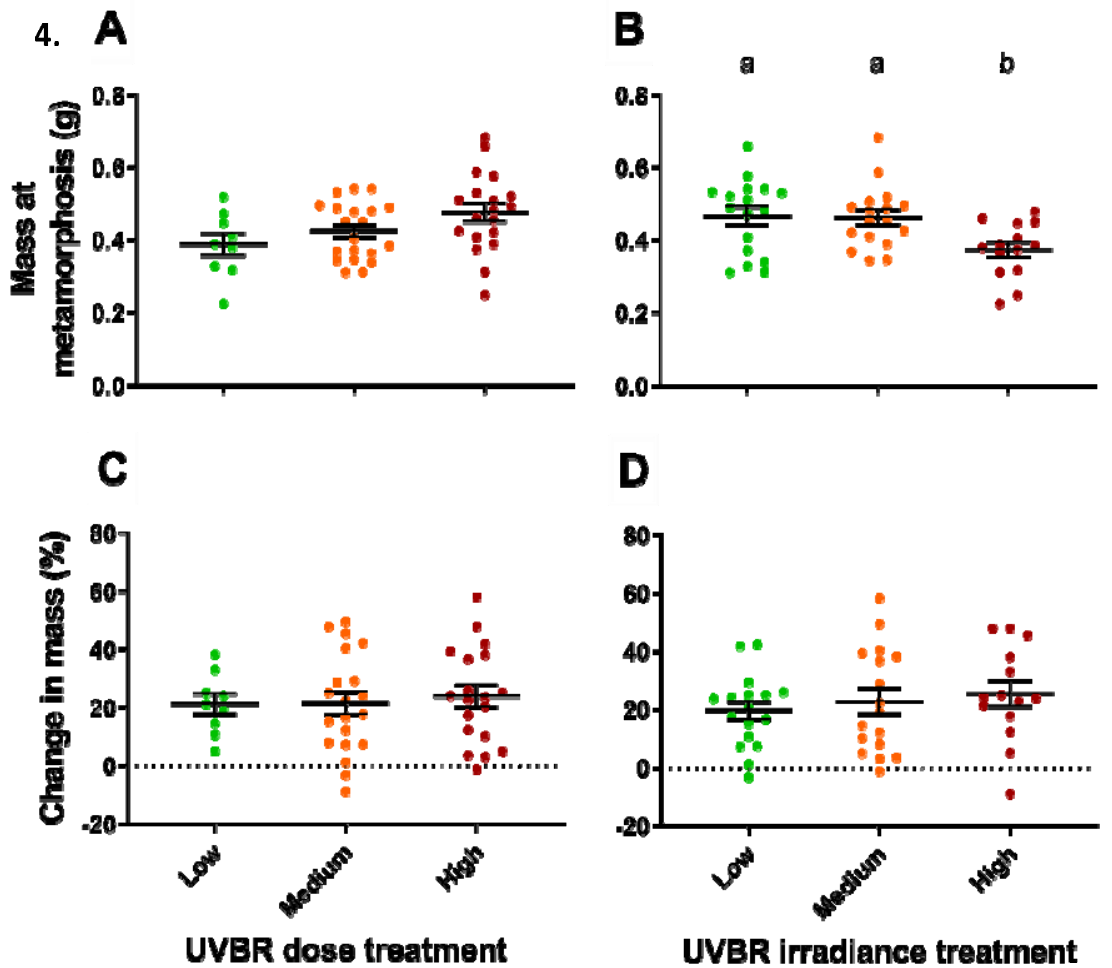

Figure 4. Effect of UVBR dose and irradiance (pooled) on mass at metamorphosis (g; A and $\mathrm{B}$, respectively) and growth after metamorphosis ( $\mathrm{C}$ and $\mathrm{D}$, respectively) of $L$. caerulea metamorphs ( $n=9-20$ per pooled treatment level). Growth after metamorphosis was measured as a percentage change in mass after 30 days, with no net change in mass indicated by the grey dotted line. Data are presented as means \pm s.e.m., and lowercase letters denote significant differences $(P<0.05)$ between treatment groups. 


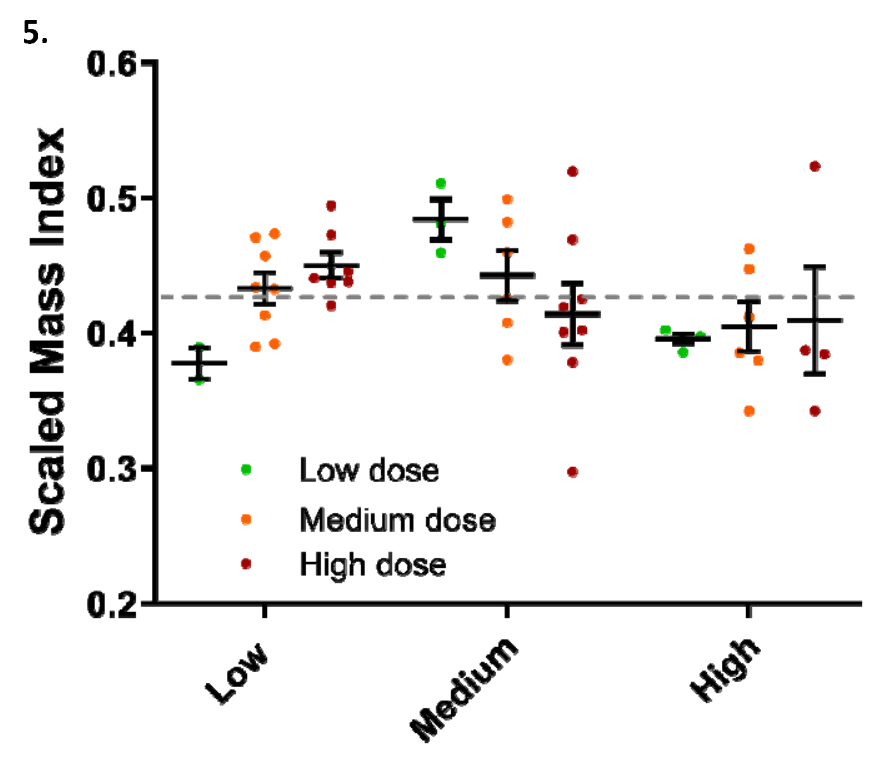

Figure 5. Effect of UVBR dose (colours) and irradiance (columns) on body condition (scaled mass index method; SMI) of $L$. caerulea metamorphs ( $n=2-8$ per treatment). SMI values represent the estimated mass (g) when scaled to the mean interorbital distance of the sample population. Data points represent individual animals, and error bars indicate treatment means \pm s.e.m. The grey dashed line represents the mean SMI of the sample population, such that points above the line indicate good relative body condition, while points below the line indicate poor relative body condition.

6. A

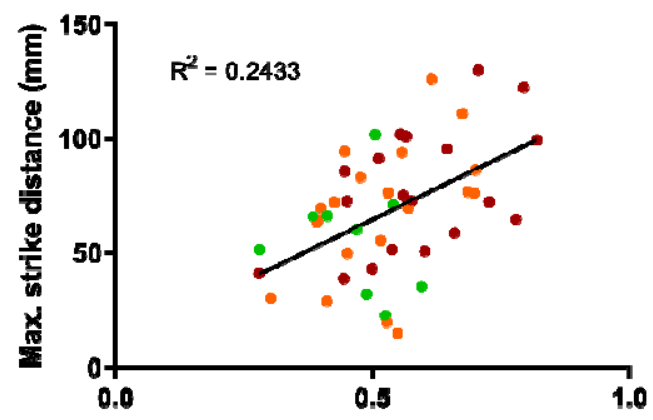

B

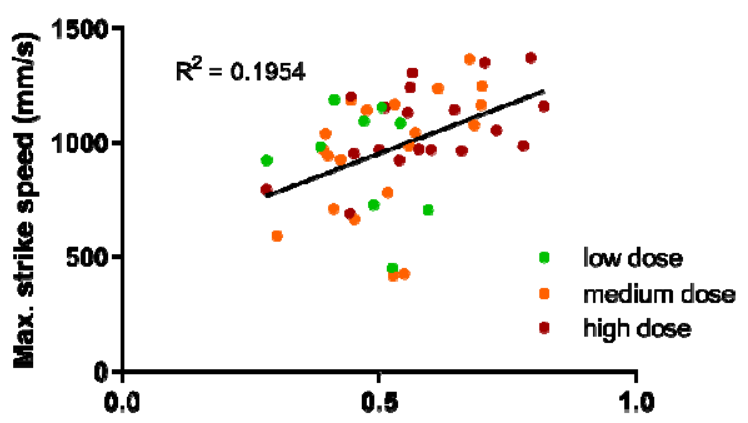

851 Figure 6. Correlation between mass (g) of $L$. caerulea frogs 1-month postmetamorphosis, and foraging performance metrics (maximum strike distance [mm] (A) and speed $[\mathrm{mm} / \mathrm{s}](B)$ of successful prey capture). Data points represent individual animals, color-coded by UVBR dose treatment $(n=9-20$ per irradiance, pooled across UVBR doses). Trend lines indicates a moderate positive correlation between mass and foraging performance. 


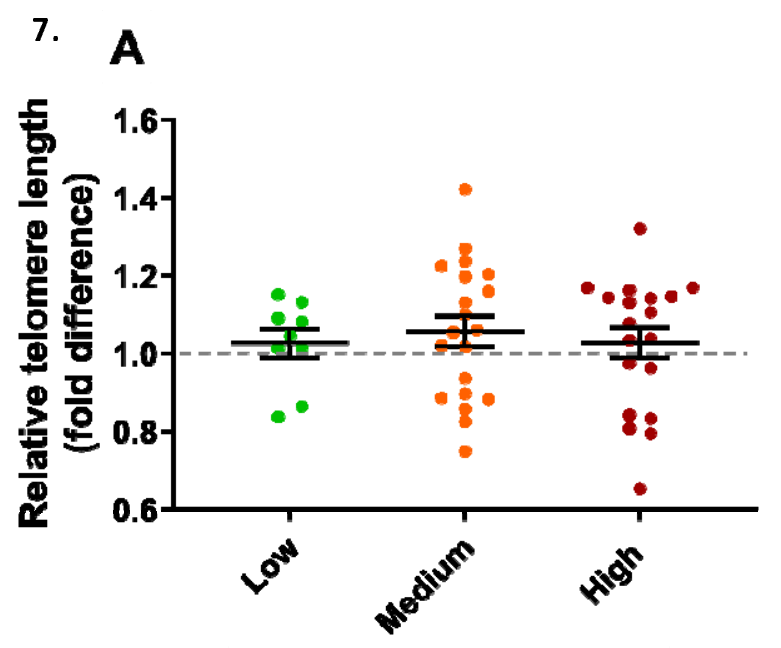

UVBR dose treatment
B

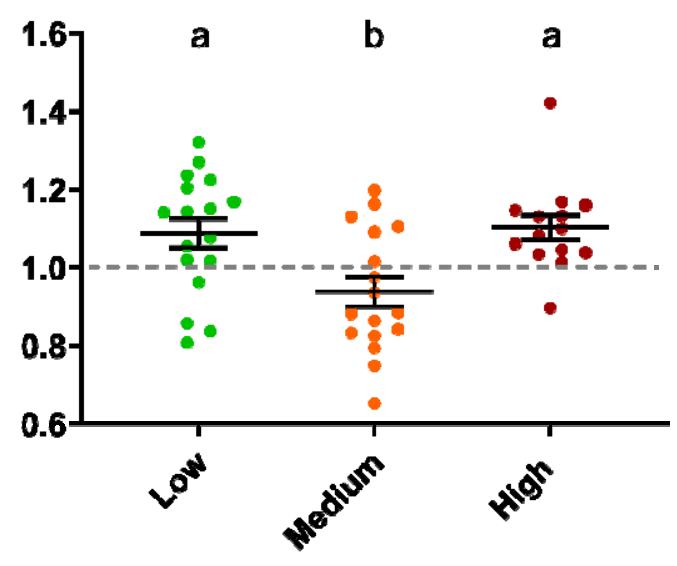

UVBR Irradlance treatment

Figure 7. Effect of UVBR dose (A) and irradiance (B) pooled across the levels of the

859 other factor, on relative telomere lengths of $L$. caerulea juveniles 1 month post-

860 metamorphosis $(n=9-20$ per pooled treatment level), as a fold difference from the

861 reference sample (a pool of all samples, indicated by the grey dashed line). Data are

862 presented as means \pm s.e.m., and lowercase letters denote significant differences $(P<0.05)$

863 between treatment groups. 